\title{
Ecological Efficiency Evaluation and Spatiotemporal Characteristics Analysis of the Coupling Coordination of the Logistics Industry and Manufacturing Industry
}

\author{
Juan Su \\ Chang'an University \\ Tong Shen \\ Chang'an University \\ shuxin jin ( $\square$ jinshx3@mail.sysu.edu.cn ) \\ Sun Yat-Sen University https://orcid.org/0000-0002-0425-4863
}

\section{Research Article}

Keywords: Ecological efficiency, Logistics industry, Manufacturing industry, Spatiotemporal characteristics, Spatial econometric model

Posted Date: December 2nd, 2021

DOI: https://doi.org/10.21203/rs.3.rs-1109799/v1

License: (c) (1) This work is licensed under a Creative Commons Attribution 4.0 International License.

Read Full License 


\section{Ecological efficiency evaluation and spatiotemporal characteristics analysis of the coupling coordination of the logistics industry and manufacturing industry}

1 Juan $\mathrm{Su}^{1}$, Tong $\mathrm{Shen}^{2}$, Shuxin $\mathrm{Jin}^{3}{ }^{3, *}$

$2{ }^{1}$ College of Transportation Engineering, Key Laboratory of Transport Industry of Management,

3 Control and Cycle Repair Technology for Traffic Network Facilities in Ecological Security Barrier

4 Area, Chang'an University, Xi'an, 710064, China;

${ }^{2}$ College of Equipment and Support, Engineering University of PAP, Xi'an 710086, China;

${ }^{3}$ School of Intelligent Systems Engineering, Sun Yat-Sen University, Guangzhou, 510006, China;

7 * Correspondence:

8 Shuxin Jin

9 jinshx3@mail.sysu.edu.cn

\section{Abstract}

The coupling coordination of the logistics industry and manufacturing industry conducive to the sustainable development of logistics and manufacturing and the stability of sustainable supply chain. The logistics and manufacturing industries are not only the basic industries that support social development, but also the industries with high carbon emissions. Firstly, this paper classifies the carbon emissions from the logistics industry and manufacturing industry as undesirable outputs, evaluates the ecological efficiency of the logistics industry (LEE) and manufacturing industry (MEE) in the Yangtze River Delta from 2006 to 2019 by using the unexpected slacks-based measure (SBM) model. Secondly, the coupling coordination method is used to analyze the coupling coordination scheduling of industrial ecological efficiency. Thirdly, the paper analyzes the spatial differences of the coupling coordination ecological efficiency between logistics industry and manufacturing industry (MLCC) by using the exploratory spatial data analysis method. Finally, the spatial econometric model is used to analyze the driving factors of the MLCC. The results show: The ecological efficiency of the manufacturing industry has steadily improved. The ecological efficiency of the logistics industry presents the rising trend in fluctuation. The level of the coupling coordination development between the logistics and manufacturing industries is high. The results of the spatial heterogeneity analysis show that the spatial differentiation of high-high agglomeration and low-low agglomeration is obvious. The spatial agglomeration characteristics are relatively stable, and the spatial diffusion effect is strong; In space, the MLCC shows a trend of developing from multiple agglomeration areas to one agglomeration area. The results of driving factor analysis show that foreign direct investment(FDI), government intervention(GI) and human capital(HP) have positive effects on the MLCC, while industrial structure(IS), environmental regulation(ER) and energy intensity(EI) have negative effects on the MLCC.

33 Keywords: Ecological efficiency; Logistics industry; Manufacturing industry; Spatiotemporal characteristics; Spatial econometric model. 
At present, with the rapid development of the social economy, China's logistics demand is increasing rapidly, and the scale of logistics is expanding rapidly. How to continuously improve the quality of the logistics industry while reducing energy consumption and carbon dioxide emissions is an urgent problem to be considered. Similarly, while China's manufacturing industry has made great achievements, it has also encountered various environmental problems in the process of industrialization similar to developed countries in recent centuries. The extensive economic growth mode of high input and high-energy consumption leads to the problems of low-resource utilization efficiency and the aggravation of environmental pollution (De Koster,2003).

The logistics and manufacturing industries have a naturally close relationship; they influence each other and develop interactively(W.L. Zheng et al., 2020). Under the background of a new round of technological innovation and industrial reform, logistics industry and manufacturing industry are undergoing the transformation from traditional industry to digital industry(Kaur et al., 2017). The coupling coordination of the logistics and manufacturing industries determines the sustainable development level of the "two industries" and the comprehensive competitiveness of the regional economy. It is conducive to the sustainable development of logistics and manufacturing and the stability of sustainable supply chain. In recent years, the development trend of coupling coordination and integration between China's logistics and manufacturing industries has increased, but the degree of integration is not high enough, the scope is not wide enough, and the degree is not deep enough, which does not meet the general requirements of promoting the formation of a strong domestic market, building a modern economic system, and adapting to the new pattern of "double cycle" development(Notice,2020).

According to the statistics of IEA database, the global power and heat production industry contributes $42 \%$ of carbon dioxide emissions, and the industry (including manufacturing, construction and non-fuel mining) and transportation industry contribute $18.4 \%$ and $24.6 \%$ respectively. In China, industry and transportation contributed $27.9 \%$ and $9.7 \%$ respectively. In 2020 , China put forward the goal of striving to reach the peak of carbon dioxide emission by 2030 and achieving carbon neutralization by 2060(Hu,2021). At the same time, China's economy has entered the stage of high-quality development, and the cultivation of industrial clusters with international competitiveness has become a new power source to achieve high-quality economic development. In 2018, the integrated development of the Yangtze River Delta became a national strategy. The Yangtze River Delta is an important gathering area for China's advanced manufacturing industry. Through informatization, networking and the integration effect of modern logistics, the logistics cost of manufacturing enterprises can be effectively reduced, and more resources can be concentrated to develop the core competitiveness of the manufacturing industry. Therefore, it is of great practical significance to study the development of the coupling coordination between the logistics and manufacturing industries to promote the transformation and upgrading of the manufacturing industry in the Yangtze River Delta region, to achieve the goal of "made in China 2025" and to realize the high-quality development of the regional economy. It is further conducive to achieving the goal of reaching the carbon peak in 2030.

Since the concept of ecological benefit was first proposed by schartger and Sturm (1990), in recent years, many scholars have studied ecological efficiency (Zhou et al., 2015) (Watanabe and Tanaka, 2007: Wang Bing et al., 2010). The two directions related to this paper are logistics industry efficiency and manufacturing industry efficiency. 
(1) In terms of the ecological efficiency of the logistics industry:

Long (2020) used carbon dioxide emissions as undesirable outputs to evaluate the logistics ecological efficiency. Zhang Linlin (2019) used SBM undesirable model to measure the efficiency of China's logistics industry under low-carbon constraints, and the panel Tobit model was used to empirically analyze its influencing factors. The results show that the overall efficiency of China's logistics industry is at the upper middle level, with obvious regional differences.

(2) In terms of the ecological efficiency of the manufacturing industry:

Zhang Feng (2019) constructs a three-stage efficiency measurement model of advanced manufacturing green technology innovation by using nonmandatory range adjustment and stochastic frontier functions and measures its green technology innovation efficiency based on manufacturing panel data. The results show that the overall efficiency of green technology innovation in the national advanced manufacturing industry is still low, and the capital intensity and industry profit rate have a significantly positive effect on the efficiency of green technology innovation in the advanced manufacturing industry. Han Jing (2014) Using the directional distance function, the ecological efficiency level of the manufacturing industry is calculated under the condition of considering the energy input and undesirable outputs. The research shows that the ecological efficiency of China's manufacturing industry is on the rise, but it is significantly lower than that without considering resource input and negative environmental output. The ecological efficiency level of the manufacturing industry shows obvious industry heterogeneity.

Recently, various studies have focused on production sector for estimation of resources, climatic and institutional barriers in the land use (Elahi et al., 2021ab; Elahi et al., 2019abcd; Elahi et al., 2018). Some studies for instance (Peng et al., 2020ab; Peng et al., 2019ab; Peng et al., 2018; Huang Q et al., 2020; Wang Y et al., 2019) have focused on ecological security, ecological footprint, ecological carrying capacity and ecological environmental vulnerability. However, ecological efficiency evaluation and spatiotemporal characteristics analysis of the coupling coordination development of the logistics industry and manufacturing industry has not been explored yet. Therefore, the current article aims to determine the ecological efficiency of the coupling coordination development of logistics industry and manufacturing industry considering environmental effects, as well as the spatial model (spatial heterogeneity, spatial agglomeration and driver analysis) and trend dynamic evolution of the coupling coordination development efficiency of the two industries.

The potential academic contributions of this paper are as follows: (1) The coupling coordination measurement system of logistics industry and manufacturing industry considering carbon emission is established. (2) This paper analyzes the spatial effect of the coupling coordination degree between logistics industry and manufacturing industry by using spatial correlation model, and discusses the influencing factors of coupling coordination by using spatial econometric model. The analysis has certain policy guidance and theoretical significance. The rest of this study is as follows. The second part presents introduces the relevant models. The third part explains the indicators and unexpected data. The fourth part presents the empirical analysis. Finally, this paper summarizes the conclusions and discusses relevant suggestions.

\section{MODEL INTRODUCTION}

\subsection{Coupling coordination model of logistics industry and manufacturing industry}


The coupling coordination Coupling degree indicates the degree of mutual influence between two or more systems or elements due to interaction. Coupling coordination degree is the horizontal embodiment of mutual promotion and benign interaction between systems. In recent years, the theory of coupling coordination has been widely used in many fields of transportation, such as control operation strategy, planning strategy, predictive control and so on. In the composite system composed of logistics industry and manufacturing industry, the coordinated development of two industries refers to the evolution of two subsystems and their components towards a harmonious and consistent direction, and the coupling of two industries refers to the mutual influence and interaction between two subsystems and their components. The order parameters in the two-industry complex system are the fundamental variables that determine the evolution trend of the system. The key to the evolution of the two-industry complex system is the synergy between the internal order parameters, and the coupling coordination degree is the measure reflecting the synergy.

$$
C=2\left\{\left(U_{1} \mathrm{~g}_{2}\right) /\left(U_{1}+U_{2}\right)^{2}\right\}^{1 / 2}
$$

Where, $C$ represents the coupling degree; $U_{1}$ and $U_{2}$ represent the comprehensive order parameters of logistics and manufacturing respectively, expressed by logistics efficiency and manufacturing efficiency under low-carbon constraints.

The coupling degree $\mathrm{C}$ cannot reflect the overall level of logistics efficiency and manufacturing efficiency and the synergy between them. For example, when the logistics efficiency and manufacturing efficiency are very low, the coupling degree will be very high. Therefore, based on relevant research results, a coupling coordination degree model is constructed:

$$
D=\sqrt{C \mathrm{~g} T}, T=\alpha U_{1}+\beta U_{2}(4)
$$

Where, D represents coupling coordination degree; $\mathrm{C}$ represents coupling degree; $\mathrm{T}$ represents the comprehensive coordination index of logistics efficiency and manufacturing efficiency under lowcarbon constraints; $\alpha$ and $\beta$ are undetermined parameters, and are assigned 0.5 respectively according to the practices of most scholars. The coupling coordination degree is between 0 and 1 , and the median segmentation method is adopted to divide the coupling coordination degree into five grades (Table 1).

148 TABLE 1 | Hierarchical division of coupling coordination degree

\begin{tabular}{ccccc}
\hline Severe & Moderate disorder & Slight coordination & Good coordination & Highly coordination \\
disorder & & & & \\
\hline $0<\gamma_{i j} \leq 0.2$ & $0.2<\gamma_{i j} \leq 0.4$ & $0.4<\gamma_{i j} \leq 0.6$ & $0.6<\gamma_{i j} \leq 0.8$ & $0.8<\gamma_{i j} \leq 1$ \\
\hline
\end{tabular}


In order to give consideration to the generality and rationality of the index system, this paper selects the comprehensive technical efficiency as the decision-making basis for evaluating the comprehensive order parameters of logistics industry and manufacturing industry.

In view of the heterogeneity of production technology in the Yangtze River Delta, this paper uses the common frontier model based on SBM method to measure the comprehensive technical efficiency of manufacturing and logistics industry. The calculation is realized with MaxDEA ultra7.0 software.

\subsection{Spatial diffusion effect model}

1) Global spatial correlation

Global spatial correlation is used to analyze the spatial association and spatial difference of the research object and to determine whether there is spatial diffusion. It is generally measured by the global Moran index (Moran,1953).

$$
I=\frac{\sum_{i=1}^{n} \sum_{j=1}^{n} W_{i j}\left(x_{i}-\bar{x}\right)\left(x_{j}-\bar{x}\right)}{s^{2} \sum_{i=1}^{n} \sum_{j=1}^{n} W_{i j}}
$$

163

where $\mathrm{I}$ is the Moran index and, $s^{2}=\frac{1}{n} \sum_{i=1}^{n}\left(Y_{i}-\bar{Y}\right)^{2}, \bar{Y}=\frac{1}{n} \sum_{i=1}^{n} Y_{i}, \mathrm{X}_{\mathrm{i}}$ and $\mathrm{X}_{\mathrm{j}}$ are the coupling coordination efficiency values of the logistics industry and manufacturing industry of cities I and $\mathrm{j}$, respectively. According to the calculation results of Moran's I statistics, the normal distribution hypothesis can be used for testing. Finally, the significance level of spatial autocorrelation is tested by using the standardized statistic Z:

$$
Z(d)=\frac{\text { moran }^{\prime} I-E(I)}{\sqrt{\operatorname{VAR}(I)}}
$$

According to the spatial distribution, the expected value of standardized Moran's I was calculated

$$
E(I)=-\frac{1}{n-1}
$$

The variance of normal distribution is as follows:

$$
\operatorname{VAR}(I)=\frac{n^{2} w_{1}+n w_{2}+3 w_{0}^{2}}{w_{0}^{2}\left(n^{2}-1\right)}-E^{2}(I)
$$

where $\mathrm{E}(\mathrm{I})$ is the expectation of autocorrelation of observation variables, and VAR (I) is the variance. $\mathrm{W}_{\mathrm{I}}$ and $\mathrm{W}_{\mathrm{J}}$ refer to the sum of columns $\mathrm{I}$ and $\mathrm{j}$ in the spatial weight matrix, respectively, indicating the proximity of spatial positions $\mathrm{I}$ and $\mathrm{J}$. When $\mathrm{I}$ and $\mathrm{j}$ are adjacent, $\mathrm{W}_{\mathrm{ij}}=1$, and vice versa. The value range of Moran index is $[-1,1]$. When $\mathrm{I}>0$, it means that there is a positive correlation in each region; when $I=0$, it means that there is no spatial correlation in each region; and when $\mathrm{I}<0$, it indicates that there is a negative correlation in each city (completed by ArcGIS 10.2, used to analyze the diffusion characteristics of logistics industrial efficiency, manufacturing industrial efficiency and coupling coordination efficiency of the two industries). 
182 Local spatial autocorrelation is the local expression of Moran index, which is the test form of 183 agglomeration and dispersion effect of local area. It reflects the correlation degree between the 184 attribute value of a region and the attribute value of adjacent region.

$$
I_{i}=\frac{\left(x_{i}-\bar{x}\right)}{s^{2}} \sum_{j=1}^{n} w_{i j}\left(x_{j}-\bar{x}\right)
$$

Where: Ii is the local Moran index of area I, and other parameters are the same as above.

187 If $\mathrm{I}_{\mathrm{i}}$ is greater than 0 , it means that the local area and the surrounding area present similar spatial 188 agglomeration (high high or low low agglomeration). If $\mathrm{I}_{\mathrm{i}}$ is less than 0 , it shows different spatial 189 agglomeration (high low or low high agglomeration). The cluster of regions can be directly analyzed 190 by Moran scatter diagram, and the local Moran index is still tested by Z statistic.

\subsection{Spatial econometric model}

Common spatial measurement models include: spatial lag model (SLM), spatial error model (SEM) and spatial Durbin model (SDM) (Elhorst, 2014; Liu et al.,2017). When spatial correlation exists in

$$
\mathrm{Z}=\mathrm{X}_{\alpha}+\delta \mathrm{W}_{\mu}+\varepsilon, \quad \varepsilon \in \mathrm{N}\left(0, \delta^{2}\right)
$$

$\mathrm{Z}$ indicates explained variables and is the vector of $(\mathrm{n} \times 1)$; $\mathrm{X}$ indicates explanatory variables, $\alpha$ indicates the regression coefficient, and is the vector of $(\mathrm{k} \times 1) ; \mu$ indicates the random error vector; $\delta$ is the coefficient of spatial correlation between regression residuals; $\mathrm{W}$ indicates the spatial weight matrix $(\mathrm{n} \times \mathrm{n})$; and $\varepsilon$ indicates distributed random terms independently. If the model has significant dependence between explained variables and would affect its results, using SLM model, which can be expressed as follows:

$$
\mathrm{Z}=\rho \mathrm{WY}+\mathrm{X}_{\alpha}+\varepsilon, \quad \varepsilon \in \mathrm{N}\left(0, \quad \delta^{2}\right)
$$

$\rho$ indicates the coefficient of endogenous interaction effects (WY), with its size representing the 204 degree of spatial diffusion and spatial dependence. A significant value shows that definite spatial dependence exists in explained variables. If the model considers both the endogenous interaction effect of the error term and the endogenous interaction effect of explained variables, then using SDM, which can be expressed as follows:

$$
\mathrm{Z}=\rho \mathrm{WY}+\mathrm{X}_{\alpha}+\mathrm{WX} \theta+\varepsilon, \quad \varepsilon \in \mathrm{N}\left(0, \delta^{2}\right)
$$

\section{3.INDICATORS AND UNDESIRABLE OUTPUTS DATA}

\section{$212 \quad 3.1$ Selection of indicators}

213 With reference to most very weak research on the coupling coordination efficiency of these two

214 industries, combined with some selection principles (significance, practicability, data availability, isotropy, etc.) of the indicator system, the manufacturing-and-logistics-industry, coupling coordination-development, efficiency-evaluation, index system is constructed from the perspective of input and output (Ji Xiaoli et al.,2018; Liang Hongyan et al.,2015; Chen Chunming et al.,2020). The 
218 data used in this study mainly come from the China Statistical Yearbook, the statistical yearbooks of

219 the provinces, the National Bureau of Statistics, the China Industrial Statistical Yearbook, the China

220 Environmental Statistical Yearbook, the China Energy Statistical Yearbook and the school library.

221 Due to the availability of data, the transportation industry and warehousing, postal and

222 telecommunications industrial data are generally used as logistics industrial data (since China has not

223 yet established a relatively complete statistical system for the logistics industry, and the statistical

224 caliber of the logistics industry in each country is not the same, the model and index selection in this

225 paper are only applicable to a single country or region with unified logistics industrial data statistics).

226 The specific selection indicators are as follows.

227 TABLE 2 | Index System of Manufacturing Industry Ecological Efficiency

\begin{tabular}{|c|c|c|c|}
\hline Evaluation system & Index type & Name of index & Unit \\
\hline \multirow{5}{*}{ Manufacturing system } & \multirow[t]{2}{*}{ Input indicators } & $\begin{array}{l}\text { The number of } \\
\text { employees on the job in } \\
\text { the manufacturing } \\
\text { industry }\end{array}$ & $\begin{array}{c}\text { Ten thousand } \\
\text { people }\end{array}$ \\
\hline & & $\begin{array}{c}\text { Total assets of industrial } \\
\text { enterprises above } \\
\text { designated size }\end{array}$ & 100 million \\
\hline & \multirow{2}{*}{$\begin{array}{l}\text { Output } \\
\text { indicators }\end{array}$} & industrial added value & 100 million \\
\hline & & $\begin{array}{l}\text { Main business income of } \\
\text { industrial enterprises } \\
\text { above designated size }\end{array}$ & 100 million \\
\hline & Undesirable outputs & $\begin{array}{c}\text { Carbon Emissions from } \\
\text { Manufacturing }\end{array}$ & Tons \\
\hline
\end{tabular}

229 TABLE 3 | Index System of Logistics Industry Ecological efficiency

\begin{tabular}{llcc}
\hline Evaluation system & Index type & Name of index & Unit \\
\hline Input indicators & $\begin{array}{c}\text { Number of employees in } \\
\text { the logistics industry }\end{array}$ & $\begin{array}{c}\text { Ten thousand } \\
\text { people }\end{array}$ \\
\cline { 2 - 3 } & Fixed capital investment & 100 million \\
\cline { 2 - 3 } & energy consumption & $\begin{array}{c}\text { Ten thousand } \\
\text { tons of standard } \\
\text { coal }\end{array}$ \\
\hline
\end{tabular}




\begin{tabular}{|c|c|c|c|}
\hline \multirow{5}{*}{ Logistics system } & Output & highway freight volume & Tons \\
\hline & indicators & & \\
\hline & & GDP of logistics industry & 100 million \\
\hline & & Cargo turnover & Million ton-km \\
\hline & Undesirable outputs & $\begin{array}{c}\text { Carbon Emissions from } \\
\text { Transportation }\end{array}$ & tons \\
\hline
\end{tabular}

230 The coupling coordination efficiency of logistics industry and manufacturing industry is the 231 comparative relationship between input and output or between cost and income in the process of 232 business activities of the whole system formed by logistics industry and manufacturing industry.

233 Therefore, the ecological efficiency of the coupling coordination between the manufacturing industry 234 and the logistics industry means that the ecological efficiency of the logistics industry and the 235 manufacturing industry are input factors to each other, which has an impact on the system. Therefore, 236 refer to the research methods of Wang Zhenzhen (2017), on the basis of Table 2 and table 3, after 237 considering the impact of both sides on each other, the index system as shown in Table 4 is 238 constructed (Wang Zhenzhen et al.,2017).

239 TABLE 4 | The Ecological efficiency Index of the Coupling Coordination Between Logistics 240 Industry and Manufacturing Industry

\begin{tabular}{|c|c|c|c|}
\hline Evaluation system & Index type & Name of index & Unit \\
\hline \multirow{5}{*}{$\begin{array}{l}\text { System of Logistics } \\
\text { Industry and } \\
\text { Manufacturing Industry } \\
\text { coupling coordination } \\
\text { efficiency }\end{array}$} & \multirow[t]{5}{*}{ Input indicators } & $\begin{array}{l}\text { Number of employees in } \\
\text { the logistics industry }\end{array}$ & $\begin{array}{l}\text { Ten thousand } \\
\text { people }\end{array}$ \\
\hline & & Fixed capital investment & 100 million \\
\hline & & energy consumption & $\begin{array}{l}\text { Ten thousand } \\
\text { tons of standard } \\
\text { coal }\end{array}$ \\
\hline & & $\begin{array}{l}\text { The number of } \\
\text { employees on the job in } \\
\text { the manufacturing } \\
\text { industry }\end{array}$ & $\begin{array}{l}\text { Ten thousand } \\
\text { people }\end{array}$ \\
\hline & & $\begin{array}{c}\text { Total assets of industrial } \\
\text { enterprises above } \\
\text { designated size }\end{array}$ & 100 million \\
\hline
\end{tabular}




\begin{tabular}{|c|c|c|}
\hline \multirow{5}{*}{$\begin{array}{l}\text { Output } \\
\text { indicators }\end{array}$} & highway freight volume & Tons \\
\hline & GDP of logistics industry & 100 million \\
\hline & Cargo turnover & Million ton-km \\
\hline & industrial added value & 100 million \\
\hline & $\begin{array}{l}\text { Main business income of } \\
\text { industrial enterprises } \\
\text { above designated size }\end{array}$ & 100 million \\
\hline \multirow[t]{2}{*}{ Undesirable outputs } & $\begin{array}{c}\text { Carbon Emissions from } \\
\text { Transportation }\end{array}$ & Tons \\
\hline & $\begin{array}{l}\text { Carbon Emissions from } \\
\text { Manufacturing }\end{array}$ & Tons \\
\hline
\end{tabular}

241 TABLE 5 | Variable Description for Spatial Econometric Model.

\begin{tabular}{ccc}
\hline Variable & Description & Unit \\
\hline Logistics eco-efficiency (LE) & $\begin{array}{c}\text { Logistics ecological efficiency ( } \\
\text { The results are obtained by SBM } \\
\text { model and table 1) }\end{array}$ & ratio \\
\hline $\begin{array}{c}\text { Manufacturing eco-efficiency } \\
\text { (ME) }\end{array}$ & $\begin{array}{c}\text { Manufacturing eco-efficiency (The } \\
\text { results are obtained by SBM model } \\
\text { and table 2) }\end{array}$ & ratio \\
\hline $\begin{array}{c}\text { Manufacturing and Logistics } \\
\text { Coupling coordination eco- } \\
\text { efficiency (MLCC) }\end{array}$ & $\begin{array}{c}\text { Coupling coordination eco- } \\
\text { efficiency (The results are } \\
\text { obtained by SBM model and table 3 }\end{array}$ & $\%$ \\
\hline Industrial Structure (IS) & $\begin{array}{l}\text { The added value of the secondary } \\
\text { industry as the proportion of the } \\
\text { regional GDP }\end{array}$ & $\%$ \\
\hline Government Intervention (GI) & The proportion of public finance \\
expenditure to regional GDP & \\
\hline
\end{tabular}


Foreign Direct Investment (FDI))

Total import and export trade as a percentage of GDP
$\%$

ratio

Energy Intensity (EI)

The ratio of the logistics total energy

consumption of the total turnover of

freight

Human Capital (HC)
The average number of years of education in each city thousand

ratio

Environmental Regulation (ER)

The ratio of total investment in

industrial pollutants to GDP

242

243

244

245

246

247

248

249

250

251

252

253

254

255

256

257

258

259

260

261

262

263

264

265

266

267

268

269

\subsection{Undesirable outputs data}

\section{(1) the concept of desirable Outputs and undesirable 0utputs}

In the production process of general economic system, we always hope that the smaller the input is, the better the output is. That is to say, we can produce as many outputs as possible with the smallest input, and the relative efficiency of production unit is also higher. The core idea of traditional DEA model in dealing with input-output in efficiency evaluation is also based on this. The output mentioned here is the expected output, which is the main purpose of economic production, and refers to the output with benefit. However, the production process will inevitably produce some negative effects on economic development, people do not want to produce output. The output mentioned here is undesirable outputs, that is, the output that people do not expect. It is a subsidiary product of economic production, which means the output that is not beneficial or even harmful. For example, the paper products industry, while producing, emits industrial wastewater, waste gas, waste and other pollutants. The paper or paper products here are called expected output, and industrial wastewater, waste gas, waste and other pollutants are called undesirable outputs. Considering environmental variables and paying attention to undesirable outputs will have important theoretical and practical significance for transforming the mode of economic development, strengthening environmental protection, promoting sustainable development, and establishing a saving and efficient industry.

\section{(2) the undesirable Outputs data of manufacturing industry and logistics industry}

This paper takes the $\mathrm{CO}_{2}$ emissions of logistics industry and manufacturing industry as the unexpected output index. Refer to Xu (2019), Zhang Shiqing (2017), Zheng WL (2018) and other relevant scholars' research on carbon emissions from logistics and manufacturing. Firstly, the primary energy consumption of 21 fuels mainly consumed by logistics and manufacturing industries such as raw coal, diesel, kerosene, gasoline, fuel oil, liquefied petroleum and natural gas is selected and converted into standard coal as the total energy source consumption of the two industries. Then, the above seven energy consumption are converted according to the carbon emission coefficient in the guidelines for national greenhouse gas emission inventories of the climate change Commission (IPCC), and the $\mathrm{CO}_{2}$ emissions of logistics industry and manufacturing industry are obtained respectively. The calculation formula is: 
271 Where $\mathrm{i}$ is the type of fuel, $\mathrm{E}_{\mathrm{i}}$ is the consumption of $\mathrm{i}$ fuels, $\mathrm{CF}_{\mathrm{i}}$ is the calorific value of $\mathrm{i}$ fuels, $\mathrm{CC}_{\mathrm{i}}$ is 272 the carbon content of $\mathrm{i}$ fuels, and $\mathrm{COF}_{\mathrm{i}}$ is the oxidation factor of the fuel.

\section{4.EMPIRICAL ANALYSIS}

\section{$274 \quad 4.1$ Evaluate the overall efficiency value}

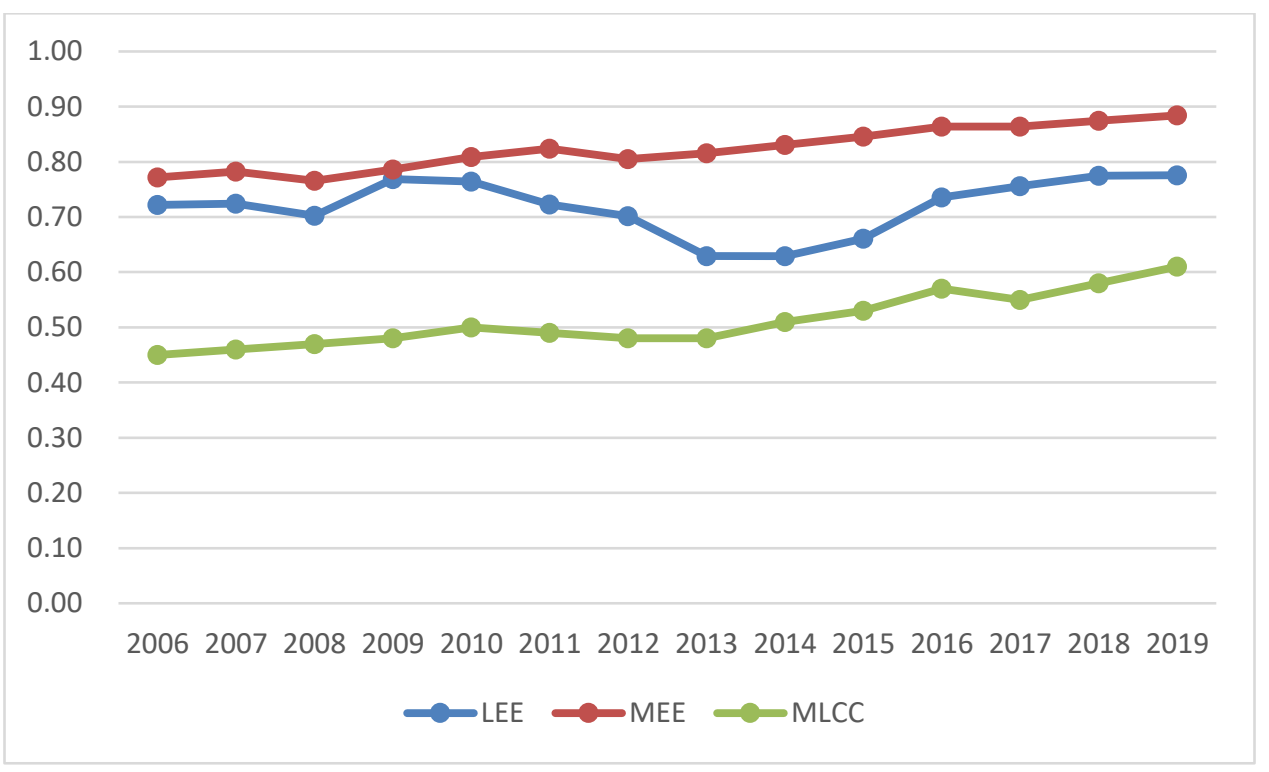

FIGURE 1 | The efficiency changing trend of the logistics industry, manufacturing industry and

The calculation results of the LEE, MEE and MLEE are shown in Figure 1. (1) From 2006 to 2019, the efficiency of the manufacturing industry in the Yangtze River Delta was stable. From 2006 to 20011, it increased slightly; it decreased slightly in 2012; from 2012 to 2019, it began to rise steadily and reached the highest value in 2019. (2) From 2006 to 2019, the efficiency of the logistics industry in the Yangtze River Delta increased slightly. It increased slightly from 2006 to 2010 and decreased significantly from 2011 to 2014. The reason may be that carbon emissions are included in the 12th Five Year Plan (2011-2015) as a binding indicator, and 2013 is the year of mid-term assessment of the 12th Five Year Plan for national environmental protection. However, the completion of carbon emission indicators in 2013 lags behind the requirements of time progress, so the situation is very serious. In response to this situation, the State Council issued the notice of 《The action plan for energy conservation, emission reduction and low carbon development for 2014-2015》, which requires to strengthen energy conservation and carbon reduction in transportation (Xuan,2015). Therefore, Lee is constrained by mandatory carbon emissions, resulting in a significant decline in Lee. After efficiency reached the lowest value in 2014, it rapidly increased to the highest value in 2019. The reason may be that during the 13th Five Year Plan period (2016-2020), China accelerated its support for the new energy vehicle industry, significantly increased the proportion of electric trucks, and gradually improved the carbon emission efficiency of the logistics industry, resulting in a significant increase in Lee. 
297 1) Empirical analysis of global spatial autocorrelation

298

299

300

301

302

303

304

305

306

307

308

309

310

311

312

313
Utilizing ArcGIS 10.2 software, the data of the logistics and manufacturing industries in 25 cities in the Yangtze River Delta from 2006 to 2019 are calculated, and Moran's I value and its standardized Z value are obtained (see Table 6). The results show that the index of the logistics and manufacturing industries of 25 cities in the Yangtze River Delta is positively correlated. The $\mathrm{Z}$ value for each year is positive, and the p-value is less than $\alpha(0.05)$, which indicates that the spatial autocorrelation is significant. This indicates that the regions with similar development levels (high or low) of the logistics and manufacturing industries in the Yangtze River Delta are concentrated in space; that is, the cities with higher coupling coordination levels of the two industries have higher coupling coordination levels of the two industries in their peripheral cities, and vice versa. From 2006 to 2019, the Moran index of the logistics and manufacturing industry in the Yangtze River Delta showed a trend of first rising and then declining, but the $\mathrm{Z}$ value of the coupling coordination efficiency of the two industries was greater than 5, indicating that the spatial distribution of the logistics and manufacturing industries in the Yangtze River Delta during this period showed a globally significant similar level of agglomeration characteristics.

TABLE 6 | Global autocorrelation analysis of coupling coordination efficiency between logistics industry and manufacturing industry in Yangtze River Delta

\begin{tabular}{lccccc}
\hline Name & Year & $\begin{array}{c}\text { Moran's } \\
\text { Index }\end{array}$ & Z Score & P-value & $\begin{array}{c}\text { Agglomerati } \\
\text { on }\end{array}$ \\
\hline $\begin{array}{l}\text { Coupling coordination } \\
\text { efficiency of logistics } \\
\text { industry and } \\
\text { manufacturing industry }\end{array}$ & 2006 & 0.5457 & 5.2465 & 0.01 & Yes \\
& 2013 & 0.5867 & 6.5684 & 0.01 & Yes \\
\hline
\end{tabular}

2) Empirical analysis of local spatial autocorrelation

In order to reflect the spatial structure changes of logistics industry and manufacturing industry in the Yangtze River Delta region from 2006 to 2019, according to the local spatial autocorrelation analysis method, this paper selects the coupling coordination efficiency of logistics industry and manufacturing industry in 2006, 2013 and 2019 as the research data, and analyzes the spatial characteristics and changes of the coupling coordination efficiency between each city and adjacent cities in the Yangtze River Delta region. The results (Table 7) show that there is an obvious spatial distribution pattern of logistics and manufacturing industry in the Yangtze River Delta.

TABLE 7 The results of Lisa analysis on the coupling coordination efficiency of logistics industry and manufacturing industry in the Yangtze River Delta in 2006, 2013 and 2019
2006
2013
2019 
High-High(HH) Nanjing, Shanghai

High-Low(HL) Wenzhou

Low-High (LH) Jiaxing, Taizhou

Low-Low(LL)
Lishui, Suqian
Nanjing, Shanghai

Wenzhou

Jiaxing, Taizhou

Lishui, Suqian
Nanjing, Shanghai, Hangzhou

Wenzhou

Jiaxing

Lishui, Suqian

According to the results of Lisa, each city is divided into four quadrants according to its nature. As shown in Table 7, this paper selects several representative cities for analysis.

The first quadrant is the $\mathrm{HH}$ agglomeration type of logistics and manufacturing coupling coordination ecological efficiency. The cities in this quadrant have relatively large local Moran values, and the local Moran values of the surrounding cities are also relatively large. That is to say, the logistics and manufacturing coupling coordination efficiency of this city is relatively high, and it has a significant positive impact on the logistics and manufacturing coupling coordination efficiency of neighboring cities The high value area of industry coupling coordination efficiency is surrounded by the same high value area, and the diffusion effect is obvious. It can be seen that the high agglomeration areas of logistics and manufacturing coupling coordination efficiency in the Yangtze River Delta are mainly concentrated in Shanghai, Hangzhou and Nanjing. By comparing 2006 and 2019 , it can be found that in 2006, they were mainly distributed in Shanghai, the provincial capital and municipality directly under the central government, and in 2019, Wuxi, Suzhou, Changzhou and other surrounding cities were added. The coupling coordination efficiency of the two industries in these cities presents a development trend from multiple agglomeration areas to one agglomeration area in space, which indicates that the coupling coordination of logistics industry and manufacturing industry in the research area has entered a relatively centralized development stage(Li Z et al.,2020).

The second quadrant is the LH agglomeration type. The local Moran value of cities in this quadrant is relatively small, and the local Moran value of surrounding cities is relatively large, that is, the cities with low coupling coordination efficiency of logistics and manufacturing industry are surrounded by high value cities. It can be seen that the low and high efficiency agglomeration areas of logistics and manufacturing in the Yangtze River Delta are mainly concentrated in Jiaxing, Taizhou and other cities. By comparing 2006 and 2016, it can be found that in 2006, they were mainly distributed in Jiaxing, a city close to Shanghai, and Taizhou, a city close to Suzhou Wuxi Changzhou economic zone. By 2016, they were reduced to only Jiaxing, and the surrounding areas of Jiaxing were developed by Shanghai, Hangzhou, Ningbo and other cities It's surrounded by the city.

The third quadrant is LL agglomeration type. The local Moran value of cities in this quadrant is relatively small, and the local Moran value of surrounding cities is also relatively small. That is to say, the coupling coordination efficiency of logistics and manufacturing in this city is low, and it has a significant negative impact on the coupling coordination efficiency of logistics and manufacturing in neighboring cities The low value area of industry coupling coordination efficiency is surrounded by the same low value area. It can be seen that the low efficiency of the coupling coordination between logistics industry and manufacturing industry in the Yangtze River Delta is mainly concentrated in the northern and southern mountainous areas, such as Suqian, Lishui, Quzhou and other cities. By comparing 2006 and 2019, we can find that the low and low concentration areas are all the cities in Northern Jiangsu and southern Zhejiang. The coupling coordination efficiency of the 
two industries in these cities presents a negative externality agglomeration in space, and these cities

361 will easily cause a vicious circle between cities and form a marginal area through the spatial spillover effect(Hackius et al.,2020; Kant K et al.,2017; Zhang Y et al.,2018; Chen J et al.,2020; J. Li et

363 al.,2018;).

364 The fourth quadrant is the HL agglomeration type. The cities in this quadrant have relatively large local Moran values, and the local Moran values of the surrounding cities are relatively small, that is, the logistics and manufacturing coupling coordination efficiency of the city is higher, and the local Moran values of the surrounding cities are relatively low, that is, the cities with high logistics and manufacturing coupling coordination efficiency are ignored Surrounded by low value cities, it has spatial spillover effect on the surrounding cities. It can be seen from Table 7 that the agglomeration areas of logistics and manufacturing coupling coordination efficiency in Yangtze River Delta are mainly concentrated in Wenzhou and other cities. By comparing 2006 and 2019, it can be found that these cities are concentrated in southern Jiangsu. There are too many low value cities around, which indicates that Wenzhou, as a big city around, has limited power to drive the efficiency of the two industries coupling coordination(Chen J et al.,2020; J.J Wang et al.,2020; Choi T M et al.,2016; Shi $\mathrm{Y}$ et al.,2016).

To sum up, the spatial agglomeration attribute of logistics and manufacturing coupling coordination efficiency in Yangtze River Delta is relatively stable, and the spatial diffusion effect is strong. In recent years, the rise of Suzhou, Wuxi and Changzhou makes the Yangtze River delta form a development trend from multiple agglomeration areas to relatively concentrated agglomeration areas. Jiaxing and Taizhou are the typical cities in the Low-High agglomeration type. These cities are in the transition zone of Shanghai, Nanjing and Hangzhou megalopolis, surrounded by these developed cities, and are the transition zone of the study area megalopolis for factor flow. Lishui and Suqian are typical cities in Low-Low cluster type. The development level of logistics industry in these cities is backward, the foundation of manufacturing industry is poor, and the coupling coordination efficiency of the two industries in the surrounding areas is also low, which is easy to form marginal areas. The typical city in High-Low agglomeration type is Wenzhou, where the export-oriented economy is developed and the manufacturing industry has a good foundation, resulting in spatial spillover effect(Jiang P et al.,2018; He D et al.,2020; John E et al.,2018).

\subsection{Empirical analysis of spatial econometrics}

According to the previous analysis, the spatial autocorrelation test of coupling coordination efficiency of logistics industry and manufacturing industry indicates that it exists a spatial agglomeration. To find a proper spatial econometric model, this paper use (robust) lagrange multipliers (LM) test, the likelihood ratio (LR) test, the Wald test and Hausman test (Table 8).

394 TABLE 8 | Estimation results without spatial interactive effects

\begin{tabular}{ccccc}
\hline & $\begin{array}{c}\text { Mixed OLS } \\
\text { estimator }\end{array}$ & $\begin{array}{c}\text { Spatial fixed } \\
\text { effect }\end{array}$ & $\begin{array}{c}\text { Temporal fixed } \\
\text { effect }\end{array}$ & $\begin{array}{c}\text { Temporal and spatial } \\
\text { double fixed effect }\end{array}$ \\
\hline LM_lag & $3.98^{* *}$ & $37.81^{* * *}$ & 8.84 & $11.61^{*}$
\end{tabular}



R_LM_lag

LM_error

$3.12 * *$

$29.63 * * *$

6.23

$3.84 *$

R_LM_error

1.48

12.14

1.98

1.77

\begin{tabular}{ccc}
\hline Wald_spatial_lag & $15.506 * *$ & $18.632 * *$ \\
LR_spatial_lag & $13.454 * *$ & $17.563 * *$ \\
Wald_spatial_error & $18.647 * *$ & $19.457 * * *$ \\
& $18.345 * *$ & $17.864 * *$ \\
LR_spatial_error & &
\end{tabular}

Hausman test

$39.497,15,0.001$

LR spatial fixed

$614.303,30,0.000$

effects

LR time fixed

$289.531,12,0.000$

effects

395 Note: the data are from the model regression, and the results are sorted out by the author, *, **, ***, 396 respectively, indicating the significance level of $0.1,0.05$ and 0.01 .

397 LM test results show that the spatial lag effect is more significant than the spatial error effect.

398 Therefore, it is more suitable to use spatial Durbin model.

399 It is noteworthy that the coefficients of the SDM model do not directly reflect the marginal effects of

400 the corresponding explanatory variables on the dependent variable (LeSage and Pace, 2010), so it 401 needs to verify spatial effects from the total effect, the direct effects and indirect effect (Table 9).

402 TABLE 9 | Estimation and test results based on Spatial Durbin model (SDM) for the driving factor Spatial Durbin model (SDM) for the driving factor

\begin{tabular}{lllll} 
& Coefficient & Direct & Indirect & Total \\
\hline LnIS & $-0.051^{* *}$ & $-0.019 * * *$ & -0.056 & $-0.075^{* * * *}$
\end{tabular}




\begin{tabular}{|c|c|c|c|c|}
\hline & $(-1.904)$ & $(-0.154)$ & $(-0.322)$ & $(-0.323)$ \\
\hline \multirow{2}{*}{ LnFDI } & $0.046 * * *$ & 0.116 & 0.057 & 0.173 \\
\hline & $(5.172)$ & $(0.564)$ & $(0.261)$ & $(0.844)$ \\
\hline \multirow{2}{*}{ LnER } & $-0.031 * * *$ & $-0.027 * *$ & -0.005 & -0.032 \\
\hline & $(-2.943)$ & $(-0.278)$ & $(-0.685)$ & $(-0.844)$ \\
\hline \multirow{2}{*}{ LnGI } & $0.046 * * *$ & $0.046^{* * *}$ & $0.337 * * *$ & $0.383 * * *$ \\
\hline & $(5.172)$ & $(1.214)$ & $(0.475)$ & $(0.527)$ \\
\hline \multirow{2}{*}{ LnEI } & $-0.009 * * *$ & $-0.028 * * *$ & $-0.124 * * *$ & $-0.152 * * *$ \\
\hline & $(-2.543)$ & $(-1.141)$ & $(-0.439)$ & $(-0.549)$ \\
\hline \multirow{2}{*}{ LnHC } & $0.032 * * *$ & $0.193^{* * *} *$ & $0.421 * * *$ & $0.614 * * *$ \\
\hline & $(2.743)$ & (1.233) & $(1.242)$ & $(1.267)$ \\
\hline \multirow{2}{*}{$\mathrm{W}^{*} \operatorname{LnIS}$} & -0.006 & & & \\
\hline & $(-0.324)$ & & & \\
\hline \multirow{2}{*}{$\mathrm{W}^{*} \mathrm{LnFDI}$} & $0.098 * *$ & & & \\
\hline & $(1.889)$ & & & \\
\hline \multirow{2}{*}{$\mathrm{W}^{*} \operatorname{LnER}$} & $0.097 * * *$ & & & \\
\hline & (9.979) & & & \\
\hline \multirow{2}{*}{$\mathrm{W}^{*} \mathrm{LnGI}$} & $-0.002 * * *$ & & & \\
\hline & $(-2.834)$ & & & \\
\hline \multirow{2}{*}{$\mathrm{W}^{*} \mathrm{LnEI}$} & $0.065^{* * *}$ & & & \\
\hline & $(4.645)$ & & & \\
\hline $\mathrm{W}^{*} \mathrm{LnHC}$ & $-0.001 * *$ & & & \\
\hline
\end{tabular}


$\mathrm{W} * \mathrm{LnLE} \quad 0.019 * * *$

\section{(1.998)}

$\mathrm{W} * \mathrm{LnME}$

$0.034 * * *$

$(1.443)$

$\mathrm{W}^{*} \operatorname{LnMLCC}$

$0.325 * * *$

(4.033)

$* * *$ Significance level at $1 \%$. **Significance level at 5\%. ${ }^{*}$ Significance level at $10 \%$.

404 The regression results show in Table 8, the industrial structure (IS) has a negative impact on the 405 coupling coordination ecological efficiency, it fully shows that the increase in the proportion of 406 China's logistics industry and manufacturing industry has a negative effect on ecological efficiency. 407 With the acceleration of industrialization, the secondary industry drives economic growth will not 408 change in a short period of time.

409 Foreign direct investment (FDI) is the invisible driving force of the logistics industry and 410 manufacturing industry development. Foreign direct investment increases 1\%, coupling coordination ecological efficiency will increase $0.116 \%$, the hypothesis of "polluting heaven" is not established. This is mainly because in the process of logistics and manufacturing transformation, China gives priority to the development of green logistics and advocates green production. Relevant documents have been formulated and very strict measures have been taken for pollution prevention and ecological protection. In addition, we should pay more attention to the introduction of high-quality foreign investment and strengthen the examination and approval of foreign investment. The spillover effect of high-quality foreign capital is conducive to improving the coupling coordination ecological efficiency of logistics industry and manufacturing industry in the Yangtze River Delta.

Environmental regulation (ER) has a negative impact on the improvement of logistics ecological efficiency, the higher the intensity of environmental regulation, the lower the logistics ecological efficiency. The in efficiency of environmental regulation is caused by the decentralized governance structure and the performance appraisal mechanism. This leads to the "race-to-the-bottom" competition of local governments in the process of enacting and implementing environmental regulations. Because environmental pollution is external and can be transmitted between regions, even if strict environmental regulations are implemented in this region, it will not necessarily reduce the damage caused by environmental pollution.

427 The government intervention (GI) direct coefficient is 0.046, indicating that the current government intervention has a positive impact on the coupling coordination ecological efficiency. The problems existing in the coupling coordination development of logistics industry and manufacturing industry are that the degree of marketization is not enough, the direct information asymmetry of the two industries, and the willingness of active cooperation is still not high. Therefore, government 
433 logistics and manufacturing industries, continuously guiding the two industries to actively cooperate,

434 and improving the coupling coordination efficiency of the two industries.

435 The energy intensity (EI) direct coefficient is -0.028 , indicating that the energy intensity has a

436 significant negative effect on the improvement of logistics ecological efficiency. The greater the

437 energy intensity, the stronger the dependence of logistics industry and manufacturing industry on

438

439

440 energy and also the greater the energy consumption. At the same time, the proportion of clean energy used in China's logistics industry is small. Therefore, high energy consumption and high carbon emission restrict the efficient and sustainable development of logistics industry.

441 Human capital (HC) direct coefficient is 0.193 , indicating that the human capital has a positive 442 impact on coupling coordination ecological efficiency. The indirect coefficient of human capital is 0.421 , indicating that human capital has a positive spillover effect. The result shows that the higher the education level of the labor force in a certain city, the more propitious it is to promote the progress of coupling coordination ecological efficiency in neighboring city. This is related to the development stage of logistics and manufacturing in the Yangtze River Delta. At present, the Yangtze River Delta is the most active region in China's economic development and the leading region of high-tech development. The logistics industry and manufacturing industry have gradually crossed the primary stage driven by material capital and labor input, and entered the growth stage driven by human capital and core technology.

\section{CONCLUSION}

452 In this paper, the ecological efficiency of logistics and manufacturing industry is evaluated by SBM model; The coupling coordination method is used to analyze the MLCC. The spatial heterogeneity and spatial aggregation of the MLCC are analyzed by the spatial correlation analysis; The driving factors of the MLCC are analyzed by using the spatial measurement method. It provides theoretical reference and decision support for improving the coupling coordination efficiency of logistics and manufacturing industry in Yangtze River Delta. The results show that:

The calculation results of industrial coupling coordination ecological efficiency show that: the ecological efficiency of the manufacturing industry in the study area has steadily improved; the ecological efficiency of the logistics industry has fluctuated greatly, first rising, then falling, and finally steadily improving; the deviation of the ecological efficiency curve between the logistics and manufacturing industries shows that when considering the undesirable outputs, the logistics and manufacturing industries cannot achieve an absolutely high level of coupling coordination development during the research period, but the ecological efficiency of the logistics and manufacturing industries is relatively stable. The coupling coordination development is at a high level.

467 The results from spatial heterogeneity show that there is a positive spatial correlation between the indexes of the logistics and manufacturing of 25 cities in the Yangtze River Delta. Areas with similar development levels (high or low) of the logistics and manufacturing industries are concentrated in space. From 2006 to 2019, the Moran index of the logistics and manufacturing industries in the Yangtze River Delta region showed a trend of first rising and then declining, which indicates that the spatial distribution of the logistics and manufacturing industries showed a significantly similar level of agglomeration characteristics.

474 The results of the local spatial autocorrelation analysis show that: The coupling coordination

475 ecological efficiency of the two industries in the Yangtze River Delta presents a development trend 
from multiple agglomeration areas to one agglomeration area in space, which indicates that the coupling coordination of logistics industry and manufacturing industry in the Yangtze River Delta has entered a relatively centralized development stage.

479 The results of empirical analysis of spatial econometrics show that FDI, GI and HC have positive 480 effects on the coupling coordination ecological efficiency of the two industries, while IS, ER and EI 481 have negative effects on the coupling coordination ecological efficiency of the two industries.

\section{SUGGESTIONS AND POLICY IMPLICATIONS}

According to the above research conclusion, this paper presents some suggestions for the coupling coordination development of the logistics and manufacturing industries in the Yangtze River Delta region.

First, although the efficiency of the regional logistics industry is at a high level, this still cannot meet the needs of the manufacturing industry, and the coupling coordination ecological efficiency of the two industries lags behind the efficiency of the manufacturing industry. Therefore, in order to improve the level of coupling coordination development, it needs to continue to make greater effort to develop high-end logistics dominated by high-tech; which can greatly improve the service level, specialization level and economies of scale that are advantageous for logistics enterprises; and to help the manufacturing industry to reduce costs and to improve efficiency.

Second, the transformation and upgrading of the local manufacturing industry needs to continue to be promoted. Although the efficiency of the manufacturing industry in the research area is at a high level, there is still room for development. In the future, the transformation and upgrading of China's manufacturing industry should be promoted under the guidance of the Internet of Things, Blockchain, artificial intelligence, big data, cloud computing and other advanced technologies to achieve the goal of "made in China 2025".

Third, it is increasing concern to society about the environment impact of the development of the logistics and manufacturing industries. The development policies of the logistics and manufacturing industries formulated by relevant managers should not only consider the economic benefits but also consider the impact on the environment.

Fourth, energy conservation and emission-reduction technology should be promoted. In order to achieve the goal of reaching the carbon peak by 2030, the government should increase investment in the development of energy-saving and emission-reduction technology, enhance the exchange of advanced technology and the management experience of energy savings and environmental protection, actively develop and promote energy savings and emission-reduction technology to effectively improve the increasingly serious problem of environmental pollution.

514 The limitations of this paper include the following. Regarding research data acquisition: because the 515 logistics industry is a network industry involved in many other industries, currently, a systematic 516 evaluation index of the efficiency of the logistics industry is still missing; there are currently no 
authoritative logistics statistical indicators in China; and compared to urban logistics and

518 manufacturing data, the availability of undesirable outputs data is poorer.

519 Regarding future research: with the development of informatization, big data and the Internet of 520 Things, more extensive research can be conducted on index selection and data acquisition in the 521 future. This study is limited to the Yangtze River Delta region. The interaction between 'the logistics and manufacturing industries has a different development status in different regions in China. In the future, the study area can be extended to the entire country.

524 Ethical Approval and consent to participate: Not applicable

525 Consent for publication: Not applicable

526 Declarations

527 No potential conflict of interest was reported by the author(s).

528 Data availability

529 The original contributions presented in the study are included in the article/Supplementary Material, 530 further inquiries can be directed to the corresponding author.

\section{Author contributions}

532 Juan Su: designed the paper framework. Tong Shen: Writing - original draft. Shuxin Jin: Supervision.

\section{Funding}

534 This work supported by the Special Scientific Research Program of Education Department of 535 Shaanxi Province of china (Grant number 19JK0382) and Fundamental Research Funds for the 536 Central Universities, Sun Yat-sen University (Grant number 2021qntd08).

\section{Acknowledgments}

538 We are thankful for the comments and advice which are given by the reviewers. They have improved 539 the content of this work and pointed out some research directions of particular interest.

\section{References}

541 Chames, A., Cooper, W. W., \& Rhodes, E. (1978). Measuring the efficiency of decision making units.J.European journal of operational research, 2(6), 429-444.doi:10.1016/0377-2217(78)90138-8

Chen Chunming, Chen Jiaxin, Gu Jun. (2020).research on the evolution of the linkage development between manufacturing industry and logistics industry in China .J. Journal of Shandong University (philosophy and social sciences), (2). doi: 10.19836/j.cnki.37-1100/c.2020.02.008.

Chen J, Li H, Zheng T, et al. (2020). Network Evolution of Logistics Service Effect of Port Infrastructure in Coastal China.J. IEEE Access, PP.(99):1-1.

Chen J, Li H, Zheng T, et al. (2020). Network Evolution of Logistics Service Effect of Port Infrastructure in Coastal China.J. IEEE Access, PP.(99):1-1. doi: 10.1109/access.2020.2975364.

Choi T M , Wallace S W , Wang Y . (2016). Risk management and coordination in service supply chains: information, logistics and outsourcing.J. Journal of the Operational Research Society, 67(2):159-164. doi : 10.1057/jors.2015.115. 
553

554

555

556

557

558

559

560

561

562

563

564

565

566

567

568

569

570

571

572

573

574

575

576

577

578

579

580

581

582

583

584

585

586

587

588

589

590

591

592

593

594

595

596

597

598

599

600

601

602

De Koster, R.B.M. (2003). Distribution strategies for online retailers.J. IEEE Transactions on Engineering Management, 50(4):448-457. doi:10.1109/tem.820135

Elahi E , Abid M , Zhang L, et al. (2018). Agricultural advisory and financial services; farm level access, outreach and impact in a mixed cropping district of Punjab, Pakistan.J. Land Use Policy . 71: 249-260. doi: $10.1016 / j$.landusepol.2017.12.006

Elahi E, Khalid Z, Cui W , et al. (2019c).The public policy of agricultural land allotment to agrarians and its impact on crop productivity in Punjab province of Pakistan.J. Land Use Policy, 90:104324. doi: 10.1016/j.landusepol.2019.104324

Elahi E, Weijun C, Zhang H, et al. (2019d). Agricultural intensification and damages to human health in relation to agrochemicals: Application of artificial intelligence.J. Land Use Policy, 83:461-474. doi: 10.1016/j.landusepol.2019.02.023

Elahi E, Zhang H , Lirong X , et al. (2021a). Understanding cognitive and socio-psychological factors determining farmers' intentions to use improved grassland: Implications of land use policy for sustainable pasture production.J. Land Use Policy, 102. doi.org/10.1016/j.landusepol.2020.105250.

Elahi E, Khalid Z, Tauni M Z, et al. (2021b). Extreme weather events risk to crop-production and the adaptation of innovative management strategies to mitigate the risk: A retrospective survey of rural Punjab, Pakistan.J. Technovation, 102255. doi : 10.1016/j.technovation.2021.102255.

Elahi E, Weijun C, Jha S K, et al. (2019a). Estimation of realistic renewable and non-renewable energy use targets for livestock production systems utilising an artificial neural network method: A step towards livestock sustainability.J. Energy, 183: 191-204. doi: 10.1016/j.energy.2019.06.084

Elahi E, Weijun C, Zhang H, et al. (2019b). Use of artificial neural networks to rescue agrochemical-based health hazards: A resource optimisation method for cleaner crop production.J. Journal of Cleaner Production, 238: 117900. doi.org/10.1016/j.jclepro.2019.117900

Elhorst, J.P.(2014). Linear spatial dependence models for cross-section data. Spat. Econom. 9, 5-36 doi: 10.1007/978-3-642-40340-8_2.

Hackius N , Petersen M . (2020). Translating High Hopes into Tangible Benefits: How Incumbents in Supply Chain and Logistics Approach Blockchain.J. IEEE Access, 8(1):34993-35003. doi: 10.1109/access.2020.2974622.

Han Jing, Chen Chaofan, Shi Faqi. (2014). Environmental efficiency, industry heterogeneity and optimal regulation intensity of China's manufacturing industry.J. Statistical research, 31 (03): 61-67. doi: 10.19343/j.cnki.11-1302/c.2014.03.009.

He D, Yang J, Wang Z, et al. (2020). Has the manufacturing policy helped to promote the logistics industry? .J. PLOS ONE, 15. doi: 10.1371/journal.pone.0235292.

Hu Angang. ( 2021) China's goal of achieving carbon peak by 2030 and its main ways.J. Journal of Beijing University of Technology (SOCIAL SCIENCE EDITION) ,21 (03): 1-15. doi: 10.12120/bjutskxb202103001.

Huang Q, Peng B , Elahi E, et al. (2020). Evolution and Driving Mechanism of Ecological Security Pattern: A Case Study of Yangtze River Urban Agglomeration.J. Integrated Environmental Assessment and Management, doi: 10.1002/ieam.4358

J. Li, T. Li, Y. Wang. (2018). Spatial effect of regional logistics industry efficiency considering undesirable output.J.Journal of Arid Land Resources and Environment, 032 (008) :67-73. doi: 10.13448/j.cnki.jalre.2018.237

J.J Wang, M.M Wang, F. Liu. (2015). Multistakeholder Strategic Third-Party Logistics Provider Selection: A Real Case in China.J. Transportation Journal, 54(3):312-338.

Ji Xiaoli, Zhou Weijie, Ma Tao. (2018). Innovation of logistics cost management and competitiveness of manufacturing enterprises in Yangtze River Delta -- Based on the comparison of logistics efficiency between Chinese and American manufacturing industries.J. Discussion on modern economy, (8): 91-97. doi: 10.3969/j.issn.1009-2382.2018.08.012.

Jiang P, Hu Y C, Yen G F, et al. (2018). Using a Novel Grey DANP Model to Identify Interactions between Manufacturing and Logistics Industries in China.J. Sustainability, 10(10). doi: 10.3390/su10103456. 
603

604

605

606

607

608

609

610

611

612

613

614

615

616

617

618

619

620

621

622

623

624

625

626

627

628

629

630

631

632

633

634

635

636

637

638

639

640

641

642

643

644

645

646

647

648

649

650

651

652

653

John E. (2018). Spillan,Alma Mintu-Wimsatt,Ali Kara. Role of logistics strategy, coordination and customer service commitment on Chinese manufacturing firm competitiveness.J. Asia Pacific Journal of Marketing and Logistics, 30(5).

Kant K , Pal A . (2017). Internet of Perishable Logistics.J. IEEE Internet Computing, 21(1):22-31. doi: 10.1109/MIC.2017.19.

Kaur H, Singh S P. (2017). Modeling low carbon procurement and logistics in supply chain: A key towards sustainable production. .J. Sustainable Production and Consumption, 11: 5-17.

Li Z , Li Y, Lu W, et al. (2020). Crowdsourcing Logistics Pricing Optimization Model Based on DBSCAN Clustering Algorithm.J.IEEE Access, PP(99):1-1. DOI: 10.1109/ACCESS.2020.2995063.

Liang Hongyan. (2015). Research on the influence mechanism of logistics development on manufacturing efficiency .J. Southeast academic, (1): 88-97. doi: cnki:sun:dlxs.0.2015-01-012.

Liu, H., Fang, C., Bao, C., Zhang, X., Wang, Z., Li, F. (2017). The effect of natural and anthropogenic factors on haze pollution in Chinese cities: A spatial econometrics approach. J. Cleaner Prod. 165, 323-333.doi : 10.1016/j.jclepro.07.127

Long R , Ouyang H, Guo H . (2020). Super-slack-based measuring data envelopment analysis on the spatialtemporal patterns of logistics ecological efficiency using global Malmquist Index model.J.

Environmental Technology \& Innovation, 18:100770. doi: 10.1016/j.eti.2020.100770.

M. Yunshou et al., A Collaborative Demand-Controlled Operation Strategy for a Multi-Energy System [J]. IEEE Access, vol. 9, pp. 80571-80581, 2021, doi: 10.1109/ACCESS.2021.3083922.

Matlab Chinese Forum. (2010). Analysis of 30 cases of MATLAB neural network .M. Beijing University of Aeronautics and Astronautics Press.

Moran P A P . (1953). The statistical analysis of the Canadian Lynx cycle.J. Australian Journal of Zoology, 1. doi: $10.1071 /$ zo9530291

Notice on printing and distributing the implementation plan for promoting the deep integration and innovative development of logistics manufacturing industry. 2020, .J. Shanghai building materials (05), 9-12 doi:cnki : sun:shja.0.2020-05-003.

P. Chanfreut, J. M. Maestre and E. F. Camacho, Coalitional Model Predictive Control on Freeways Traffic Networks [J] IEEE Transactions on Intelligent Transportation Systems, vol. 22, no. 11, pp. 6772-6783, Nov. 2021, doi.org/10.1109/TITS.2020.2994772.

Peng B , Li Y , Elahi E, et al. (2019a). Dynamic evolution of ecological carrying capacity based on the ecological footprint theory: A case study of Jiangsu province.J. Ecological indicators, 99(APR.):19-26. doi: 10.1016/j.ecolind.2018.12.009

Peng B , Wang Y, Elahi E, et al. (2018). Evaluation and Prediction of the Ecological Footprint and Ecological Carrying Capacity for Yangtze River Urban Agglomeration Based on the Grey Model.J.

International Journal of Environmental Research and Public Health, 15(11):2543-. doi: 10.3390/ijerph15112543

Peng B , Wang Y, Zahid S , et al. (2020a). Platform ecological circle for cold chain logistics enterprises: the value co-creation analysis.J. Industrial Management \& Data Systems, ahead-of-print(ahead-of-print). doi : 10.1108/IMDS-10-2019-0531

Peng B , Zheng C, Wei G, et al. (2020b). The cultivation mechanism of green technology innovation in manufacturing industry: From the perspective of ecological niche.J. Journal of Cleaner Production, 252:119711. doi: 10.1016/j.jclepro.2019.119711

Peng, Huang, Elahi, et al. (2019b). Ecological Environment Vulnerability and Driving Force of Yangtze River Urban Agglomeration.J. Sustainability, 11(23):6623. doi: 10.3390/su11236623

Schaltegger S, Sturm A . (1990). kologische Rationalitt (German/in English: Environmental rationality) .J. Die Unternehmung, 4(4):117-131.

Shi Y , Zhang A, Arthanari T , et al. (2016). Third-party purchase: An empirical study of third-party logistics providers in China.J. International Journal of Production Economics, 171(jan.pt.2):189-200. doi: 10.1108/ijopm-11-2014-0569.

Sueyoshi T , Yuan Y, Goto M . (2016). A literature study for DEA applied to energy and environment.J. Energy Economics, 62(FEB.):104-124. doi: 10.1016/j.eneco.2016.11.006 
654

655

656

657

658

659

660

661

662

663

664

665

666

667

668

669

670

671

672

673

674

675

676

677

678

679

680

681

682

683

684

685

686

687

688

689

690

691

692

693

694

695

696

697

698

699

700

701

702

703

704

Tone, K. (2001). A slacks-based measure of efficiency in data envelopment analysis.J. European Journal of Operational Research, 130(3), 498-509. doi: 10.1016/S0377-2217(99)00407-5

Tone, K. . (2002). A slacks-based measure of super-efficiency in data envelopment analysis.J. European Journal of Operational Research, 143(1), 32-41. doi: 10.1016/S0377-2217(01)00324-1

Tone, K., (2003). Dealing with Undesirable Outputs in DEA: A Slacks2 based Measure ( SBM)Approach. .J.GR IPS Research Report Series, I-2003-0005.

W. Yang, W. Liu, C. Y. Chung and F. Wen, Coordinated Planning Strategy for Integrated Energy Systems in a District Energy Sector [J] IEEE Transactions on Sustainable Energy, vol. 11, no. 3, pp. 1807-1819, July 2020, doi: 10.1109/TSTE.2019.2941418.

W.L. Zheng, J.W. Wang, Khan S A R et al. (2020). Evaluation of Linkage Efficiency between Manufacturing Industry and Logistics Industry Considering the Output of Unexpected Pollutants.J. Air \& waste: journal of the Air \& Waste Management Association, doi:10.1080/10962247.2020.1811799.

Wang Bing, Wu Yanrui, Yan Pengfei. (2010). China's regional ecological efficiency and environmental total factor productivity growth .J. Science and technology communication, (05):95-109. doi : cnki:sun:jjyj.0.2010-05-008

Wang Y, Peng B , Wei G, et al.( 2019). Comprehensive Evaluation and Spatial Difference Analysis of Regional Ecological Carrying Capacity: A Case Study of the Yangtze River Urban Agglomeration.J.

International Journal of Environmental Research and Public Health, 16(18):3499-. doi: 10.3390/ijerph16183499

Wang Zhenzhen. (2017). Efficiency evaluation of the linkage development of China's manufacturing and logistics industry -- Based on super efficiency ccr-dea model .J. China's circulation economy, (2) doi: 10.14089/j.cnki.cn11-3664/f.2017.02.003

Watanabe M , Tanaka K . (2007). Efficiency analysis of Chinese industry: A directional distance function approach.J. Energy Policy, 35(12):6323-6331. doi: 10.1016/j.enpol.2007.07.013

$\mathrm{Xu}$ JZ, Wang MM, Guan J. study on the mechanism of energy consumption carbon emission and green innovation efficiency from the perspective of dynamic endogenous-An Empirical Analysis Based on China's equipment manufacturing industry [J]. Management review, 2019,31 (09): 81-93.

Xuan Xiaowei. Analysis of the implementation of the 12th Five Year Plan and Its Enlightenment to the formulation of the 13th five year plan.J. Regional economic review, 2015 (01): 5-12. doi: 10.14017/j.cnki.2095-5766.2015.0001.

Zhang Feng, Shi Zhiwei, song Xiaona, et al. (2019). Green technology innovation efficiency and environmental regulation threshold effect of advanced manufacturing industry .J. Progress and Countermeasures of science and technology, v.36; no.472 (12): 68-76. doi: 10.6049/kjbydc.2018100165.

Zhang Linlin. (2019). Research on the efficiency and influencing factors of China's logistics industry under the constraint of low carbon .J. Value engineering, 38 (26): 129-131. doi: cnki:sun :jzgc.0.2019-26-054.

Zhang Shiqing, Wang Jianwei, Zheng Wenlong. Analysis on temporal and spatial differences of carbon emissions and influencing factors in transportation in China [J]. Journal of environmental science, 2017, 37 (12): 4787-97.

Zhang Y, Guo Z, Lv J , et al. (2018). A Framework for Smart Production-Logistics Systems Based on CPS and Industrial IoT.J. Industrial Informatics IEEE Transactions on, 14(9):4019-4032. doi: 10.1109/TII.2018.2845683.

Zhang Z, Hui J , Shi Z, et al. (2020). Cycle Condition Identification of Loader Based on Optimized KNN Algorithm.J. IEEE Access, PP(99):1-1. doi: 10.1109/access.2020.2985052.

Zheng W L, Wang J W, Zhang S Q. (2018). Road transportation network planning and design based on the BP neural network.J. Advances in Transportation Studies, 3(2018):117-124. doi: $10.4399 / 978882552166515$.

Zheng W, Wang J, Zhang S. Analysis on carbon emission decoupling effect and driving factors of environmental pollution in China's transportation industry [J]. Chemical Engineering Transactions, 2018, 66(637-42. doi.org/10.3303/CET1866107.

Zhou P, Ang B W , Poh K L .(2008). Measuring environmental performance under different environmental DEA technologies.J. Energy Economics, 30(1):1-14. doi: 10.1016/j.eneco.2006.05.001 
Zhou Y, Zhang M X, Yang .J. (2015). A Study on the Eco-efficiency of Logistics Industry in Provincial

706 Domain Based on SE-DEA Method. Journal of Beijing Jiaotong University(Social Sciences Edition). 